\title{
Investigations on the nervous mechanisms underlying the somatosensory cervical response in man
}

\author{
EMILIO FAVALE, SANDRO RATTO, MASSIMO LEANDRI, MICHELE ABBRUZZESE
}

From the Department of Neurology, University of Genoa, Genoa, Italy

SUMMARY The main features (amplitude, latency and shape) of the cervical activity evoked by stimulation of the median nerve, recorded throughout the cervical spine, have been concurrently investigated by monopolar, bipolar longitudinal and bipolar transverse recordings. In some subjects the derivation $\mathrm{C}_{7}-\mathrm{Sn}$ (suprasternal notch) has been employed as well. A comparative evaluation of the refractory period of each component of the cervical responses under investigation has been performed to differentiate presynaptic from postsynaptic events. Additional information has been obtained by cervical activity recorded by longitudinal and transverse bipolar derivations upon stimulation of the lower limb. It was thus demonstrated that both presynaptic and postsynaptic events were responsible for the cervical sensory evoked potential, as appearing when recorded against a cranial reference (that is the upper midfrontal region). The structures involved were the brachial plexus $\left(N_{9}\right)$, the cervical roots $\left(P_{10}\right.$ and a minor part of $\left.N_{11 a}\right)$, the dorsal columns both at caudal $\left(\mathrm{N}_{11 \mathrm{a}}\right)$ and rostral $\left(\mathrm{N}_{11 \mathrm{~b}}\right)$ cervical levels, and the dorsal column nuclei $\left(\mathrm{N}_{13}\right)$. However a contribution of the spinal segmental activity to the postsynaptic portion of the cervical response, more specifically to $\mathrm{N}_{13}$, should be considered as well, though direct evidence is still inadequate.

The waveform of the cervical response evoked by stimulation of the median nerve at the wrist, as appearing when recorded against a cranial reference (either the $\operatorname{ear}^{1}$ or the upper midfrontal region ${ }^{2-4}$ ) is now well established, but the functional significance of its components is not completely understood. In particular, it is not clear whether such components are generated from fixed sites, either spinal or supraspinal, or from a travelling wave in the system of the dorsal columns. ${ }^{5}$

Intracranial components of the cervical response may be distinguished from extracranial ones by concurrent recordings over the scalp. In fact, every extracranial event recorded from the scalp, either spinal or supraspinal in origin, should change in polarity when the reference electrode is shifted from the ear to the forehead. ${ }^{1}$ This is the case with the $\mathrm{N}_{9}$, $N_{11}$ and $N_{13}$ waves, the opposite being true for $N_{14}$,

Address for reprint requests: Emilio Favale, MD, Clinica Neurologica-Via De Toni, 5, I 16132 Genova, Italy.

Received 1 January 1982 and in revised form 21 March 1982 Accepted 9 April 1982 which thus represents the first sensory evoked potential component of intracranial origin. ${ }^{6}$ It is likely, also, that the segment of the cervical response following $N_{14}$ will be entangled with both spinal and supraspinal events. ${ }^{7}$ The present views on the nervous structures involved in the origin of the cervical response (apart from the $\mathrm{N}_{9}$ component, which appears to be generated in the region of the brachial plexus $^{3}$ ) are still controversial. Evidence on the respective contribution of radicular, spinal (either segmental or conducted) and supraspinal events to the cervical response so far available is inadequate or contradictory or both.

To clarify these issues, the main features (amplitude, latency and shape) of the activity evoked by stimulation of the median nerve (at the wrist) were concurrently recorded, both monopolarly and bipolarly, throughout the cervical spine. Additional information was obtained by recording the cervical activity evoked by stimulation of the lower limb. A comparative evaluation of the refractory period of each component and/or response under investigation was also performed, in order to differentiate presynaptic from postsynaptic events. 


\section{Material and methods}

The observations were made on 13 volunteers ranging in age from 26 to 40 years. The subjects were kept relaxed on a couch in a quiet room. The median and the tibial nerves were stimulated at the wrist and at the popliteal fossa respectively, using surface electrodes (Disa 13K62) with the cathode proximal to the anode. The limbs were gently warmed by infrared lamp throughout the experiment to ensure a skin temperature of $36-38^{\circ} \mathrm{C}$. Square pulses were delivered by a Disa 14E01 Ministim stimulator (pulse duration $0.2 \mathrm{~ms}$ ) at a rate of $1 \mathrm{~Hz}$. The stimulus intensity, both at the wrist and at the popliteal fossa, was three to four times the motor threshold of the innervated muscles. Recordings were performed by means of fine subcutaneous needles with electrode impedance of 1000-2000 ohms. Simultaneous recordings of the cervical activity evoked by stimulation of the median nerve were obtained from each subject at low $\left(C_{7}\right)$, mid $\left(C_{5}\right)$ and high $\left(C_{3}\right)$ cervical levels by monopolar (fig 1), bipolar longitudinal (fig 2) and bipolar transversal (fig 3 ) derivations. In four subjects the deri-

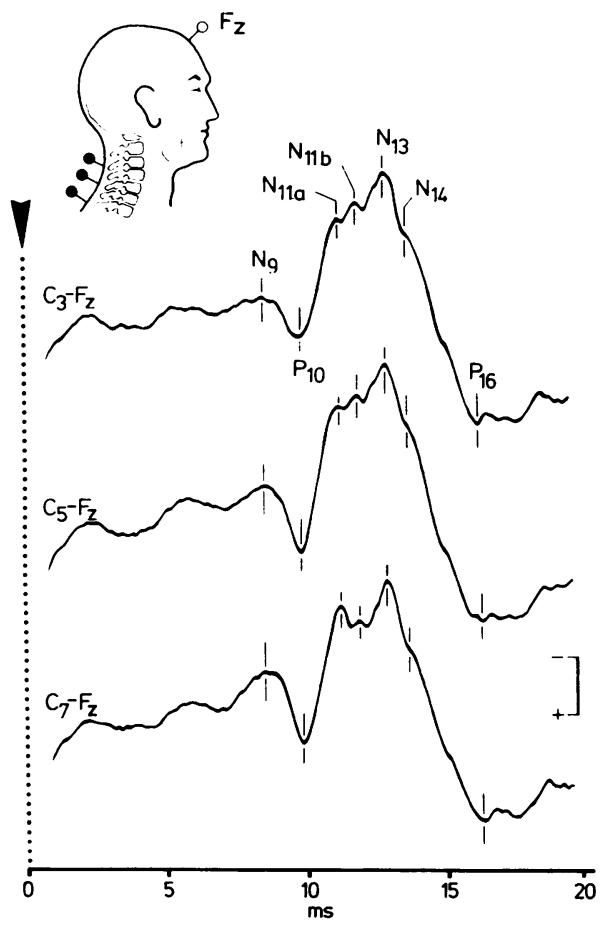

Fig 1 Cervical responses evoked by stimulation of the median nerve at the wrist simultaneously recorded at low $\left(C_{7}\right)$, mid $\left(C_{5}\right)$ and high $\left(C_{3}\right)$ cervical levels against a cranial reference $\left(F_{z}\right)$. Note that $(a)$ none of the sensory evoked potential components shifts in latency from the lower to the upper cervical level; (b) $N_{11}$ is split into two fixed latency subcomponents; (c) $N_{11 \mathrm{a}}$ is higher than $N_{11 \mathrm{~b}}$ at $C_{7}$, the opposite occurring at $C_{3}$. Calibration: $0.3 \mu \mathrm{V} ; 512$ responses were summated. vation $\mathrm{C}_{7}-\mathrm{Sn}$ (suprasternal notch) was employed as well (fig 5). The cervical activity evoked by stimulation of the lower limb was led off through longitudinal and transverse bipolar derivations at low cervical level (fig 4) in three subjects, the same interelectrode distance being used. The input from the recording electrodes was fed into differential amplifiers (Evoked potentials amplifiers Ote 2305) and simultaneously recorded on magnetic tape (Philips PM 8125). The frequency response of the recording apparatus was $16-10000 \mathrm{~Hz}(3 \mathrm{db})$. Analysis times of 20 or $50 \mathrm{~ms}$ were used and usually 512 or 1024 responses were summated. Number, shape and polarity of the recorded potentials were analysed visually. Peak latencies were measured on the plot or with a cursor on the computer oscilloscope.

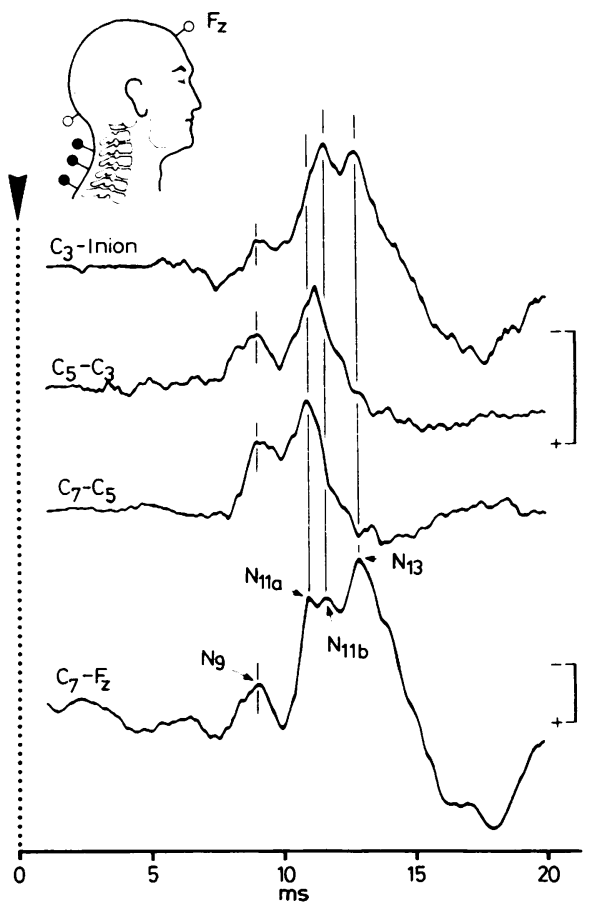

Fig 2 Cervical responses evoked by stimulation of the median nerve at the wrist, simultaneously recorded from monopolar (lower trace) and bipolar longitudinal derivations. The longitudinal recordings show: (a) a small fixed latency negative peak chronologically coincident with $\mathrm{N}_{9}$; (b) a negative peak with a variable latency shifting from lower $\left(C_{7-5}\right)$ to upper $\left(C_{3}\right.$-inion) cervical derivations with proportionally intermediate latency over the mid neck $\left(C_{5}-C_{3}\right)$; this peak is chronologically coincident with $N_{11 \mathrm{a}}$ and $N_{11 \mathrm{~b}}$ at lower and upper cervical levels respectively; (c) a peak with a fixed latency chronologically coincident with $N_{13}$, showing a reversal in polarity from $C_{7}-C_{5}$ (positive) to $\mathrm{C}_{3}$-inion (negative). Calibration: $0.3 \mu \mathrm{V} ; 1024$ responses were summated. 


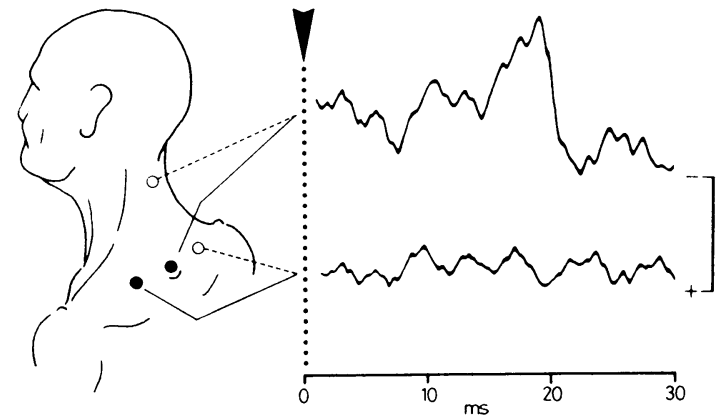

Fig 3 Concurrent neck recordings following tibial nerve stimulation at the popliteal fossa. The longitudinal derivation (upper trace) picks up a clear-cut response, while the bipolar transverse derivation (lower trace) fails to demonstrate any definite evoked activity. Calibration: 0.3 $\mu V ; 1024$ responses were summated.

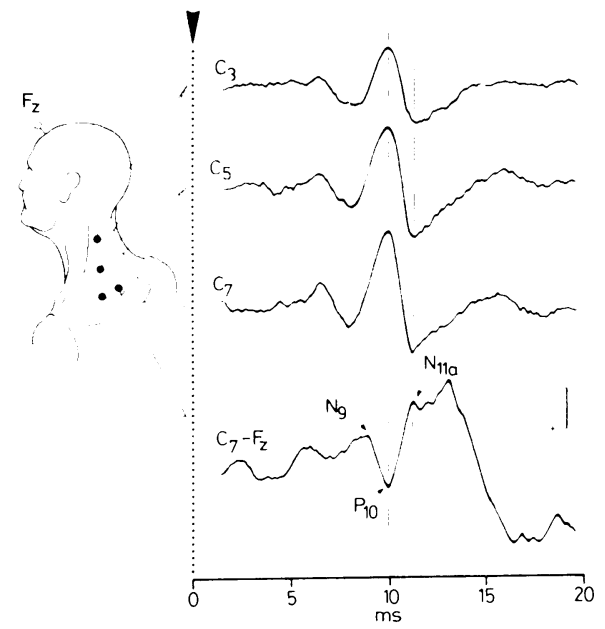

Fig 4 Cervical responses evoked by stimulation of the median nerve at the wrist, simultaneously recorded from monopolar (lower trace) and bipolar transverse derivations. The transverse recordings show: (a) a small fixed latency negative peak occurring 2-3 ms earlier than $N_{9}$; (b) a chronological coincidence of the main negative peak and the subsequent positive one respectively with $P_{10}$ and $N_{11 \mathrm{a}}$; (c) a progressive decrease in amplitude of the response from the lower $\left(C_{1}\right)$ to the upper $\left(C_{3}\right)$ cervical level. Calibration: $0.3 \mu V ; 512$ responses were summated.

\section{Results}

(A) The general waveform of the sensory evoked potential recorded over $C_{7}$ with a midfrontal reference was essentially similar to previous descriptions, being characterised by four negative components $\left(\mathrm{N}_{9}, \mathrm{~N}_{11}, \mathrm{~N}_{13}\right.$ and $\left.\mathrm{N}_{14}\right)$ followed by a slow positive deflection $\left(\mathrm{P}_{16}\right)$. Apart from a clearcut reduction in

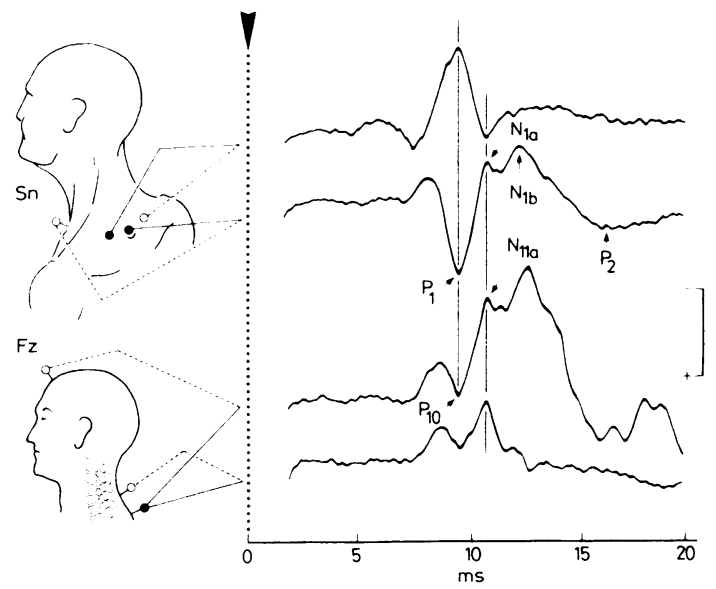

Fig 5 Concurrent recordings obtained at lower cervical level $\left(C_{7}\right)$ by four different derivations. Note that: $(a)$ both $P_{1}$ and $P_{10}$ components are chronologically coincident with the main negative peak of the transverse recording (upper trace); (b) both $N_{1 \mathrm{a}}$ and $N_{11 \mathrm{a}}$ subcomponents occur simultaneously with the main negative peak of the longitudinal recording (lower trace) as well as with the second positive peak of the transverse recording (upper trace). Calibraton: $0 \cdot 3 \mu \mathrm{V} ; 1024$ responses were summated.

amplitude of $\mathrm{N}_{9}$ at the upper cervical level, equivalent components were recorded both at $\mathrm{C}_{5}$ and $\mathrm{C}_{3}$. In addition, a small positive peak occurring between $\mathrm{N}_{9}$ and $\mathrm{N}_{11}$ could be observed, particularly when the recordings were made at $\mathrm{C}_{7}$. Currently, this peak, referred to as $P_{10}$, is not thought to be a distinct component owing to its small amplitude. None of these components shifted usually in latency from the lower to the upper cervical level. This was only partially true for $\mathrm{N}_{11}$; in the majority of cases ( 9 out of 13), $\mathbf{N}_{11}$ clearly resolved into two subcomponents with a fixed latency $\left(\mathrm{N}_{11 \mathrm{a}}\right.$ and $\left.\mathrm{N}_{11 \mathrm{~b}}\right)$ and with different amplitudes (fig 1). In particular, $\mathrm{N}_{11 \mathrm{a}}$ was higher than $\mathrm{N}_{11 \mathrm{~b}}$ in the lower neck, the opposite occurring in the upper neck. In the other cases (4 out of 13) $N_{11}$ showed a single peak the latency of which could be either unvaried ( 2 out of 13 ) or definitely longer at $C_{3}$ than at $C_{7}(2$ out of 13$)$. In a few subjects the peak of $N_{13}$ was bifid, but, at variance with $N_{11}$, no consistent amplitude distribution of the subcomponents could be observed.

(B) Sequential bipolar recordings obtained from electrode pairs (the interelectrode distance varying from 4 to $6 \mathrm{~cm}$ ) suitably positioned over the cervical spine, along the midline, were characterised by a triphasic (positive-negative-positive) potential preceded by a small fixed latency negative peak chronologically coincident with $\mathrm{N}_{9}$ (fig 2 ). The negative phase of the triphasic potential, which was generally more clearly defined than the positive ones, 
showed a significant increase in latency from the lower $(11.04 \pm 0.31 \mathrm{~ms})$ to the upper $(11.72 \pm 0.41$ ms) cervical level $(\Delta=0.68 \pm 0 \cdot 14 \mathrm{~ms} ; \mathrm{F}=67.36$, $p<0.001$, one way analysis of variance for repeated measures), with proportionally intermediate values over the mid neck $(11.37 \pm 0.30 \mathrm{~ms})$. Concurrent bipolar longitudinal and monopolar recordings (fig 2) revealed a clear coincidence of the negative phase of the cervical bipolar response, recorded at lower and upper cervical levels, with $\mathrm{N}_{11 \mathrm{a}}$ and $\mathrm{N}_{11 \mathrm{~b}}$ respectively $(11.04 \pm 0.31 \mathrm{~ms}$ vs $11.06 \pm 0.32 \mathrm{~ms}$; $11.72 \pm 0.41 \mathrm{~ms}$ vs $11.69 \pm 0.31 \mathrm{~ms}$ ). It was also found that the cervical bipolar response was constantly characterised by a small fixed latency peak, chronologically coincident with $\mathrm{N}_{13}$, which showed a clearcut polarity reversal from lower (positive) to upper (negative) neck records (fig 2).

The latency shift of the main negative phase of the cervical bipolar response could be related to the rostral propagation of afferent activity in the dorsal column, or to the sequential activation of low, mid and high cervical segments. In our subjects the mean distance between $C_{7}$ and $C_{3}$ spinous processes was $85 \pm 5 \mathrm{~mm}$, and the corresponding shift in latency was $0.68 \pm 0.14 \mathrm{~ms}$. Provided that the distance between the presumed zones of actual recording is approximately 45-50 mm (cf. Desmedt and Cheron $\left.^{8}\right)$ the values of conduction velocity can be tentatively placed at about $65-70 \mathrm{~m} / \mathrm{s}$, that is, exceedingly high for the sequential activation of cervical segments. Therefore, the latency shift most probably reflects an advancing wavefront of depolarisation in the cervical dorsal column.

(C) The possible radicular contribution to the cervical sensory evoked response was evaluated by transverse bipolar derivations performed at low, mid and high cervical levels. Such derivations are better suited to detect radicular events, which are presumably related to horizontally oriented dipoles, at least at the cervical level. Such an assumption was indirectly verified through the stimulation of the lower limb, which at the cervical level evokes exclusively cord-conducted events. It was found that, following stimulation of the tibial nerve, a clearcut response could be obtained from the longitudinal derivation $\left(\mathrm{C}_{7}-\mathrm{C}_{2}\right)$ while, as expected, no definite evoked activity could be detected from the transverse derivation at the low cervical level, although the same interelectrode distance was being used (fig 3).

The cervical response obtained from the transverse derivation upon stimulation of the median nerve was characterised by a fixed latency triphasic (positive-negative-positive) potential of progressively decreasing amplitude from the lower to the upper cervical level (fig 4). This potential was often preceded by a small, fixed latency, negative peak, apparently generated in the proximal portion of the median nerve, ${ }^{9}$ being at least $2.5 \mathrm{~ms}$ earlier than $\mathrm{N}_{9}$. Concurrent bipolar transverse and monopolar derivations showed that the main negative peak and the subsequent positive one of the transverse recordings were coincident with $P_{10}$ and $N_{11 a}$ respectively (figs 4 and 5) $(9.91 \pm 0.27 \mathrm{~ms}$ vs $9.97 \pm 0.25 \mathrm{~ms}$; $11.12 \pm 0.32 \mathrm{~ms}$ vs $11.06 \pm 0.32 \mathrm{~ms})$. Similar results have been obtained by concurrent "sagittal" $\left(\mathrm{C}_{7}-\mathrm{Sn}\right)$ and monopolar recordings (fig 5). In fact, the positive $\left(P_{1}\right)$ and negative $\left(N_{1 a}\right)$ peaks of the early positive-negative deflection of the "sagittal" response, which are held to represent the incoming volleys conducted through the cervical roots, ${ }^{10}$ were coincident with $P_{10}$ and $N_{11 a}$ respectively. As expected, $P_{1}$ and $N_{1 a}$ components coincided also with the main negative peak and the subsequent positive one of the transverse recordings (fig 5).

(D) The possible contribution of spinal potentials generated in the dorsal horn neurons, near the spinal entry of the volley, was investigated by the cervical "sagittal" derivation $\left(\mathrm{C}_{7}-\mathrm{Sn}\right)$. The negativepositive wave $\left(\mathrm{N}_{1 b}-\mathrm{P}_{2}\right)$ following the early positivenegative deflection $\left(\mathrm{P}_{1}-\mathrm{N}_{1 \mathrm{a}}\right)$ is believed to reflect the interneuronal activity and the primary afferent depolarisation in the spinal cord. ${ }^{10}$ Concurrent "sagittal" $\left(\mathrm{C}_{7}-\mathrm{Sn}\right)$ and monopolar $\left(\mathrm{C}_{7}-\mathrm{F}_{2}\right)$ recordings showed that components $\mathrm{N}_{1 b}$ and $\mathrm{P}_{2}$ are chronologically close, but not coincident, with $\mathbf{N}_{13}$ and $P_{16}$ respectively (fig 5), thus confirming our previous findings.?

(E) The results of double pulse experiments can be summarised as follows: (a) $N_{9}, P_{10}$, and $N_{11}$ had a very short refractory period. When equal paired stimuli were delivered to the median nerve at different intervals, a complete recovery could be observed within $2 \mathrm{~ms}$. Therefore, we conclude that all these components are presynaptic in origin; (b) on the contrary, $\mathrm{N}_{13}$ seemed to be postsynaptic in nature, its complete recovery never requiring less than $5 \mathrm{~ms}$; (c) no definite conclusions could be reached on the subsequent segment of the cervical monopolar response, but it seemed very likely to be postsynaptic in origin; (d) cervical responses obtained both from longitudinal (except for the peak chronologically coincident with $\mathrm{N}_{13}$ ) and transverse bipolar derivations must be considered presynaptic, since they recovered completely within $2 \mathrm{~ms}$; (e) the effect of equal paired stimuli with different interstimulus intervals on the various components of the "sagittal" response had been reported elsewhere.?

\section{Discussion}

Monopolar recordings of the cervical response evoked by stimulation of the median nerve failed to 
show consistent shifts in latency from the lower to the upper cervical spine, at least in the majority of cases, thus apparently supporting the original concept of Matthews et al, ${ }^{2}$ that is, that all the components of the cervical sensory evoked potential are generated at fixed sites. According to these authors, a possible contribution of the spinal cord pathways should be excluded, provided that in this case "both the onset and the peak latencies should be expected to be greater at more rostral recording sites". However, the peak of $\mathrm{N}_{11}$, at variance with the other components, was frequently split into two fixed latency subcomponents ${ }^{3} \quad\left(\mathrm{~N}_{11 \mathrm{a}}\right.$ and $\left.\mathrm{N}_{11 \mathrm{~b}}\right)$ which might be related to the rostral propagation of the afferent activity in the dorsal column, between $\mathrm{C}_{7}$ and $\mathrm{C}_{3}$. Indeed, sequential bipolar longitudinal recordings obtained by electrode pairs suitably positioned over the cervical spine, along the midline, demonstrated a progressive increase in latency of the cervical response to the stimulation of the upper limb. In particular, the negative peak of the triphasic potential (positive-negative-positive) picked up by bipolar longitudinal derivations shifted significantly from the lower to the upper cervical level, with proportionally intermediate values over the mid neck. This latency shift is most probably related to an advancing wavefront of depolarisation in a vertically oriented trunk situated between $\mathrm{C}_{7}$ and $\mathrm{C}_{3}$ vertebrae, rather than to a sequential activation of low, mid and high cervical segments. We were able to show that the rostral propagation of the afferent activity in the dorsal column system between $\mathrm{C}_{7}$ and $\mathrm{C}_{3}$, upon stimulation of the median nerve, can be easily demonstrated, provided that cervical longitudinal derivations are used (see also $\mathrm{Cracco}^{11}$ ). In addition, cervical monopolar recordings timed with cervical bipolar longitudinal recordings showed a clear coincidence of $\mathrm{N}_{11 \mathrm{a}}$ and $\mathrm{N}_{11 \mathrm{~b}}$ with the major negative peak of the cervical bipolar response picked up at lower and upper cervical levels respectively. Therefore, both $\mathrm{N}_{11 \mathrm{a}}$ and $\mathrm{N}_{11 \mathrm{~b}}$ could be ascribed to the volley in primary afferent fibres at caudal $\left(\mathrm{N}_{11 \mathrm{a}}\right)$ and rostral $\left(\mathrm{N}_{11 \mathrm{~b}}\right)$ levels of the cervical dorsal column, as recently suggested by Allison and Hume. ${ }^{12}$ This interpretation is supported also by the different amplitude distribution usually shown by the two subcomponents of $\mathrm{N}_{11}$. In fact, $\mathrm{N}_{11 \text { a }}$ was higher than $\mathrm{N}_{11 \mathrm{~b}}$ in the lower neck, while the opposite pattern occurred in the upper neck (see also Jones, ${ }^{3}$ fig 1 , subject SJ), possibly due to the far field conduction of the related signals from the lower to the upper cervical electrode and vice-versa. As to the unsplit cases, it is conceivable that when volume conduction is very high, $\mathrm{N}_{11 \mathrm{a}}$ and $\mathrm{N}_{11 \mathrm{~b}}$ tend to fuse into a single fixed latency peak throughout the cervical spine. On the other hand, when volume conduction is particu- larly low, the spatial and temporal separation of $\mathrm{N}_{11 \mathrm{a}}$ and $\mathrm{N}_{1 \mathrm{~b}}$ may be extremely clear (see also Allison and Hume, ${ }^{12}$ fig 3), so that a shift in latency of $N_{11}$ from the lower to the upper cervical lead can be observed. It follows that, although exceptionally, referential recordings can be suitable to detect a travelling wave, even in spite of the relatively short distance between the active electrode (i.e. $\mathrm{C}_{7}$ and $\mathrm{C}_{3}$ ) and the position of the reference (i.e. the midfrontal region).

Although both $\mathrm{N}_{11 \mathrm{a}}$ and $\mathrm{N}_{11 \mathrm{~b}}$ are very likely to reflect dorsal column activity, a radicular contribution to $\mathrm{N}_{1 \text { la }}$ should be considered as well. In fact, the reduction in amplitude of $\mathrm{N}_{11 \mathrm{a}}$ (and, to some extent, of $P_{10}$ ) in the upper neck seems to parallel the progressive decrease of the cervical transverse recordings from the lower to the upper cervical level. In this connection, it may be pointed out that: (a) transverse derivations are particularly suited to picking up horizontal dipoles, ignoring vertical ones, as demonstrated by the absence of evoked activity in the cervical transverse derivation upon stimulation of the lower limb; (b) the afferent volley to stimulation of the median nerve reaches spinal cord segments $\mathrm{C}_{7}-\mathrm{C}_{6}$ (cf Desmedt and Cheron ${ }^{8}$ ), the corresponding spinal roots being horizontally oriented; (c) such a volley could be simultaneously recorded by volume conduction even at more rostral levels, its amplitude being progressively reduced. The chronological coincidence between the cervical transverse response and the early positive-negative deflection $\left(\mathrm{P}_{1}-\mathrm{N}_{1 \mathrm{a}}\right)$ of the "sagittal" response obtained from $\mathrm{C}_{7}-\mathrm{Sn}$ derivation should be considered. This deflection is believed to represent the incoming volleys conducted through the cervical roots. ${ }^{7}$ Moreover, the simultaneous occurrence of both the transverse response and the $P_{1}-N_{1 a}$ deflection with the $\mathrm{P}_{10}-\mathrm{N}_{11 \text { a }}$ complex suggests that all of them, which are presynaptic in origin, reflect horizontally oriented dipoles, probably located at the level of the cervical roots. This conclusion does not conflict with the previous attribution of $\mathrm{N}_{11 \mathrm{a}}$ to dorsal column activity, since this component is likely to be simply contaminated by a radicular contribution. Accordingly, the equivalence $\mathrm{N}_{11}=\mathrm{N}_{1 \mathrm{a}}$ proposed by Sedgwick (personal communication)should be restated as follows: the first component of $N_{11}$ $\left(\mathrm{N}_{11 \mathrm{a}}\right)$ is partially equivalent to $\mathrm{N}_{1 \mathrm{a}}$. The postsynaptic properties of $\mathrm{N}_{11}$ previously reported by $\mathrm{El}$ Negamy and Sedgwick ${ }^{4}$ could not be confirmed by double pulse experiments. In brief we believe that the activation of the spinal roots is reflected by $P_{10}$ and, at least in part, by $\mathrm{N}_{11 \mathrm{a}}$ which incorporates both radicular and spinal conducted events, while $\mathrm{N}_{11 \mathrm{~b}}$ should be entirely related to the dorsal column activity. 
The origin of $\mathrm{N}_{13}$ cannot be established on the basis of its latency. In fact, the latter could suggest an origin of $\mathrm{N}_{13}$ either in the spinal cord, adjacent to the spinal entry, provided that one or possibly two synapses are involved, or even more rostrally, for example in the brainstem, through one synapse at the most. In patients with well localised lesions in the lemniscal pathway $\mathrm{N}_{13}$ can be preserved following thalamic ${ }^{13}$ as well as brainstem ${ }^{14}$ haemorrhage, while this component disappears after a complete spinal cord lesion at $\mathrm{C}_{5}{ }^{4}{ }^{4}$ Therefore, although the exact source of $\mathrm{N}_{13}$ is still disputed, ${ }^{8}$ it seems reasonable to conclude that $\mathrm{N}_{13}$ arises caudal to the brainstem but immediately rostral to the spinal cord. In our opinion there is little doubt that $\mathbf{N}_{13}$ is extracranial in origin since the corresponding peak recorded over the scalp changes in polarity when the reference electrode is shifted from the ear to the forehead.' The polarity reversal of $\mathrm{N}_{13}$ near the occipito-cervical junction observed in bipolar longitudinal recordings suggests that the generator of $\mathrm{N}_{13}$ could be located at this level. The clear reduction in amplitude of $\mathrm{N}_{13}$ during double pulse experiments indicates that this event is postsynaptic in origin. Finally, the unvaried latency of $\mathrm{N}_{13}$ in bipolar longitudinal recordings points to the existence of a fixed dipole probably located at the level of dorsal column nuclei, as previously suggested. ${ }^{3}{ }^{3-16}$

The latter hypothesis has been recently challenged by Mauguière and Courjon, ${ }^{17}$ who feel that $\mathrm{N}_{13}$ could originate in the dorsal horns close to the spinal entry of the volley. In fact, in one of their patients the cervical response evoked by stimulation of the right median nerve showed a negative peak at $14 \mathrm{~ms}$ though the right dorsal funiculus and related nucleus had been destroyed by a tumour down to the $C_{5}$ level. Indeed, this discrepancy with previous findings could be due to a partial contamination of $N_{13}$ with spinal segmental events, as demonstrated by concurrent "sagittal" $\left(\mathrm{C}_{7}-\mathrm{Sn}\right)$ and monopolar recordings. It was found that the negative positive wave $\left(\mathrm{N}_{1 b}-\mathrm{P}_{2}\right)$, which is held to reflect the interneuronal activity and the related primary afferent depolarisation in the spinal cord, ${ }^{10}$ is chronologically very close, although not coincident, with $N_{13}$ and $P_{16}$ respectively. ${ }^{7}$

In conclusion, both presynaptic and postsynaptic events contribute to the cervical sensory evoked potential. The structures involved are the brachial plexus $\left(\mathrm{N}_{9}\right)$, the cervical roots $\left(\mathrm{P}_{10}\right.$ and a minor part of $\left.\mathrm{N}_{11 \mathrm{a}}\right)$, the dorsal columns both at caudal $\left(\mathbf{N}_{11 \mathrm{a}}\right)$ and rostral $\left(\mathrm{N}_{11 b}\right)$ cervical levels and the dorsal column nuclei $\left(\mathrm{N}_{13}\right)$. However a possible contribution of the spinal segmental activity to the postsynaptic portion of the cervical response, more specifically to $\mathbf{N}_{13}$, should be considered as well, though direct evidence is still inadequate.

\section{References}

${ }^{1}$ Abbruzzese M, Favale E, Leandri M, Ratto S. Spinal components of the cerebral somatosensory evoked response in man: the "S wave". Acta Neurol Scand 1978;58:213-20.

${ }^{2}$ Matthews WB, Beauchamp M, Small DB. Cervical somatosensory evoked responses in man. Nature 1974;252:230-2.

${ }^{3}$ Jones SJ. Short latency potentials recorded from the neck and scalp following median nerve stimulation in man. Electroencephalogr Clin Neurophysiol 1977; 43:853-63.

4 El-Negamy E, Sedgwick EM. Properties of a spinal somatosensory evoked potential in man. $J$ Neurol Neurosurg Psychiatry 1978;41:762-8.

s Small DG, Beauchamp M, Matthews WB. Subcortical somatosensory evoked potentials in normal man and in patients with central nervous system lesions. In: Desmedt JE, ed. Clinical uses of cerebral, brainstem and spinal somatosensory evoked potentials. Progr Clin Neurophysiol. Basel: Karger, 1980;vol 7:190204.

- Abbruzzese M, Favale E, Leandri M, Ratto S. New subcortical components of the cerebral somatosensory evoked potential in man. Acta Neurol Scand 1978;58:325-32.

${ }^{7}$ Leandri M, Favale E, Ratto S, Abbruzzese M. Conducted and segmental components of the somatosensory cervical response. J Neurol Neurosurg Psychiatry 1981;44:718-22.

${ }^{8}$ Desmedt JE, Cheron G. Central somatosensory conduction in man: neural generators and interpeak latencies of far-field components recorded from neck and right or left scalp and earlobes. Electroencephalogr Clin Neurophysiol 1980;50:382-403.

9 Abbruzzese M, Favale E, Ivaldi M, Leandri M, Ratto S. Nuove acquisizioni sulla risposta cervicale somestesica. Riv Ital Elettroencef Neurofisiol 1979;2:599603.

${ }^{10}$ Shimoji K, Shimizu H, Maruyama Y. Origin of somatosensory evoked responses recorded from the cervical skin surface. J Neurosurg 1978;48:980-4.

" Cracco RQ. Spinal evoked response: peripheral nerve stimulation in man. Electroencephalogr Clin Neurophysiol 1973;35:379-86.

${ }^{12}$ Allison T, Hume AL. A comparative analysis of shortlatency somatosensory evoked potentials in man, monkey, cat and rat. Exp Neurol 1981;72:592-611.

${ }^{13}$ Hume AL, Cant BR. Conduction time in central somatosensory pathways in man. Electroencephalogr Clin Neurophysiol 1978;45:361-75.

${ }^{14}$ Chiappa KH. Pattern shift visual, brainstem auditory and short-latency somatosensory evoked potentials in multiple sclerosis. Neurology (Minneap) 1980;30: 110-23.

${ }^{15}$ Kimura J, Yamada T, Kawamura H. Central latencies of somatosensory cerebral evoked potentials. Arch Neurol 1978;35:683-8.

${ }^{16}$ Eisen A, Odusote K. Central and peripheral conduction times in multiple sclerosis. Electroencephalogr Clin Neurophysiol 1980;48:253-65.

${ }^{17}$ Mauguière F, Courjon J. The origins of short-latency somatosensory evoked potentials in humans. Ann Neurol 1981;9:607-11. 